\title{
Trends in Functional and Activity Limitations among Chinese Oldest-Old, 1998 to 2008
}

\author{
LINDA G. MARTIN \\ QIUSHI FENG \\ ROBERT F. SCHOENI \\ YI ZENG
}

WITH MORE THAN 18 million people at ages 80 and over, China was home to 17.3 percent of the world's 80 -and-over population in 2010 (United Nations 2011). Members of this group witnessed remarkable events in their lives, including the uprising against the Qing Dynasty in 1911, the war against the Japanese invasion of 1937-45, the civil war and Communist Revolution of 1946-49, the Great Leap Forward of 1958-61, the Cultural Revolution of 1966-76, and the economic reforms and growth of the last three decades.

Although population-level data are not available for the first half of the twentieth century, numerous local studies and historical records document periodic famine and unrest for substantial segments of the population (Moise 1977). The Communist Revolution led to policies to reduce social inequalities, and public health was a priority (Zhao 2006). But the Great Leap Forward and the Cultural Revolution brought social disruption, deprivation, and excess mortality (Cai and Feng 2005; Hesketh and Zhu 1997; Peng 1987). The shift from a centrally planned to a market-based economy, starting in the late 1970s, generated considerable economic growth. The shift also led, however, to increasing inequality (Yang 1999) and disruption of health care systems in both rural and urban areas (Dong and Phillips 2008; Zhao 2006), resulting in significant declines in access to care (see Du 2009 for analysis of the 1991-2000 period). Since 2003, after the epidemic of severe acute respiratory syndrome (SARS), there is evidence of substantial public investment in the health care system (Dong and Phillips 2008) and increased health care access and use (Jian et al. 2010; Meng et al. 2012).

Thus, today's oldest-old Chinese have experienced dramatic social and economic changes in their lifetimes. There have been setbacks along the way, 
but one important indicator of well-being, expectation of life at birth, has improved substantially. It is estimated that male life expectancy increased from 60.4 years in 1970 to 72.9 years in 2010, while female life expectancy rose from 63.5 to 79.0 years (Wang et al. 2012). Life expectancy at older ages has also increased substantially (Banister and Hill 2004), and causes of death have shifted from a preponderance of congenital and communicable diseases to non-communicable degenerative conditions (Yang et al. 2013).

As is the case for many other populations undergoing the epidemiological transition, there arises for China the question of whether these extra years of life are being spent in good or bad health (Fries 1980; Gruenberg 1977; Manton 1982). Are older people increasingly able to take care of themselves or are they increasingly dependent on others? The answers to these questions have implications for the well-being of individuals and their families, as well as for potential demands for private and public services.

Analysis of trends over time in the proportion of the older population with limitations in functioning and daily activities has commonly been used to examine these questions, especially in the United States and several European countries. For the 1980s and 1990s, there is strong evidence that the proportion of older Americans with limitations in their daily activities declined substantially (Manton and Gu 2001; Freedman et al. 2004), although change appears to have leveled off in the last decade (Freedman et al. 2013). In Europe, late-life functioning has generally improved, although results depend on the specific indicator tracked (e.g., Martin et al. 2012; Parker et al. 2008; Picavet and Hoeymans 2002; Sulander et al. 2006). The record on trends for Asia is thinner, primarily because of data limitations. The requirements for strong trend evidence are demanding-for example, data from the same survey for three or more time points spanning six or more years with no change in questionnaires and survey design throughout the period (Freedman, Martin, and Schoeni 2002). At least two studies of Asian populations have met those standards. A four-wave study of Japanese aged 66 and older from 1993 to 2002 found declines in difficulty with physical functions, instrumental activities of daily living (IADLs), and activities of daily living (ADLs) (Schoeni et al. 2006). An analysis of multiple waves of data for the 65-and-over population of Taiwan found that the trend in physical functional difficulties depended on the time period examined, but there were declines from 1993 to 2007 in difficulty with IADLs and no change from 1999 to 2007 in difficulty with ADLs (Martin, Zimmer, and Hurng 2011).

In this article we use data from five waves of the Chinese Longitudinal Healthy Longevity Survey (CLHLS) to assess trends in limitation of persons aged 80-105 from 1998 to 2008. The survey is remarkable in its emphasis on the oldest-old, its coverage of most of China, its large sample size, the extensive data collected, and its multiple waves. We focus on three common indicators of well-being in old age: the ability to independently perform selected physical 
functions and IADLs and the need for assistance with ADLs. The great variety of data collected in the survey also allows us to explore the extent to which trends over time in socio-demographic characteristics and early-, mid-, and late-life experiences are associated with the trends that we find. This life-course perspective is informative in view of the societal changes in China during the lifetimes of the respondents and given evidence from elsewhere that early- and mid-life experiences may affect trends in late-life functioning (Freedman et al. 2008).

\section{Data}

The CLHLS is a longitudinal survey whose initial focus in 1998 was on the 80 -and-over population in 22 of the 31 provinces of China, containing 85 percent of the total population. An attempt was made to interview all centenarians (including those in institutions) in a randomly selected half of the counties and cities in each province. For each centenarian, an octogenarian and nonagenarian living nearby were interviewed; and for each age from 80 to 99 , respondents included roughly equal numbers of males and females. The resulting sample thus over-represents males and the very oldest. In follow-up waves in 2000, 2002, 2005, and 2008, surviving respondents were re-interviewed, and, for decedents, new respondents of the same sex and similar age were recruited. For the 1998 wave, one percent of the interviews took place in 1999, and for the 2008 wave, 5 percent took place in 2009. In our estimation of average annual rates of change, we take into account differences in average intervals between survey waves.

Cross-sectional weights for respondents to each survey wave were calculated on the basis of the age, sex, and urban/rural residence distribution of the 22 provinces (CLHLS Research Group 2012). As a result, each wave of data is representative of the 22 provinces. Throughout our analysis, we use these weights, which were calculated for ages 80 to 105, and thus we treat the data as a time series of cross-sections, not as longitudinal. For 1998 to 2008, we have a pooled sample of 52,789 observations, and for 2002 to 2008, 33,012 observations. All of our models control for residence in an institution, since the survey design may have resulted in an over-representation of people in their 80 s and 90 s living in institutions.

Because of the advanced age of many of the respondents, proxy responses were allowed. Interviewers noted whether a proxy response was given for each of the function and activity outcomes that we analyze here, and we use these proxy variables as controls in our models.

The top section of Table 1 shows for 1998, 2002, and 2008 the weighted proportions of respondents who were female, members of five age groups, institutionalized, and represented by a proxy for specific outcomes. Based on analysis of data from all five waves, the population became over time increasingly less female and older. The proportion of the sample residing in 
TABLE 1 Characteristics of respondents: Weighted prevalence for 1998, 2002, and 2008, and trends in explanatory variables considered in analysis of trends in limitations (percent unless otherwise noted) ${ }^{a}$

\begin{tabular}{|c|c|c|c|c|c|}
\hline \multirow[b]{2}{*}{ Explanatory variables } & \multirow[b]{2}{*}{1998} & \multirow[b]{2}{*}{2002} & \multirow[b]{2}{*}{2008} & \multicolumn{2}{|c|}{$\begin{array}{l}\text { Significant } \\
\text { change }^{\mathrm{b}}\end{array}$} \\
\hline & & & & $\begin{array}{l}1998- \\
2008\end{array}$ & $\begin{array}{l}2002- \\
2008\end{array}$ \\
\hline \multicolumn{6}{|l|}{ Basic model } \\
\hline Female & 62.5 & 62.5 & 59.3 & down & down \\
\hline Age $80-84$ & 66.5 & 66.8 & 65.3 & - & down \\
\hline Age $85-89$ & 25.2 & 25.5 & 26.2 & - & - \\
\hline Age 90-94 & 7.1 & 6.4 & 6.9 & - & up \\
\hline Age 95-99 & 1.2 & 1.2 & 1.4 & - & up \\
\hline Age 100-105 & 0.1 & 0.1 & 0.2 & up & up \\
\hline Institutionalized & 6.6 & 5.7 & 1.6 & down & down \\
\hline Proxy any of 3 functional limitations & na & 18.7 & 18.0 & na & - \\
\hline Proxy any of 5 IADLs & na & 19.0 & 18.3 & na & - \\
\hline Proxy any of 5 ADLs & 11.2 & 20.0 & 17.1 & up & na \\
\hline \multicolumn{6}{|l|}{ Early life } \\
\hline Han ethnicity & 92.4 & 94.1 & 94.3 & up & - \\
\hline Urban birth & 17.5 & 12.9 & 11.6 & down & - \\
\hline First-born & 34.7 & 35.5 & 34.4 & - & - \\
\hline Male first-born & 12.1 & 12.6 & 13.5 & up & - \\
\hline No. of siblings (mean) & 3.3 & 3.2 & 3.2 & - & - \\
\hline Father's main occupation agriculture & 69.4 & 78.3 & 84.5 & up & up \\
\hline Adequate medical care as child ${ }^{c}$ & 81.7 & 50.5 & 31.2 & down & down \\
\hline Tap water as child & 1.8 & 1.6 & 2.1 & - & - \\
\hline Right-handed & 95.1 & 96.8 & 96.9 & up & - \\
\hline Childhood hunger & 55.7 & 65.3 & 72.7 & up & up \\
\hline 0 years of education & 62.0 & 64.9 & 63.8 & up & - \\
\hline 1 to 6 years of education & 27.1 & 26.6 & 27.7 & - & - \\
\hline 7 plus years of education & 10.5 & 7.8 & 8.3 & down & - \\
\hline
\end{tabular}

institutions declined significantly, but, as noted earlier, this pattern may not reflect the pattern for the population as a whole, but rather the sample selection of the CLHLS.

\section{Measures of limitation}

We use measures of limitation in physical functions, IADLs, and ADLs. These three indicators represent the last two stages of the disablement process, as conceptualized by Verbrugge and Jette (1994) and others. Diseases (such as arthritis) may lead to impairment (such as joint stiffness), which in turn may result in limitations in physical functions (such as walking or crouching). 
TABLE 1 (continued)

\begin{tabular}{|c|c|c|c|c|c|}
\hline \multirow[b]{2}{*}{ Explanatory variables } & \multirow[b]{2}{*}{1998} & \multirow[b]{2}{*}{2002} & \multirow[b]{2}{*}{2008} & \multicolumn{2}{|c|}{$\begin{array}{l}\text { Significant } \\
\text { change }^{\mathrm{b}}\end{array}$} \\
\hline & & & & $\begin{array}{l}1998- \\
2008 \\
\end{array}$ & $\begin{array}{l}2002- \\
2008 \\
\end{array}$ \\
\hline \multicolumn{6}{|l|}{ Mid life } \\
\hline Children ever born & 4.5 & 4.6 & 4.7 & up & - \\
\hline $\begin{array}{l}\text { Main occupation before } \\
\text { age } 60 \text { agriculture }\end{array}$ & 52.7 & 61.3 & 68.8 & up & up \\
\hline Physical labor regularly & 78.5 & 81.8 & 82.4 & up & - \\
\hline Adequate medical care at age $60^{c}$ & 96.1 & 85.6 & 80.3 & down & down \\
\hline Tap water at age 60 & 24.3 & 21.8 & 25.1 & up & up \\
\hline \multicolumn{6}{|l|}{ Late life } \\
\hline Married & 25.5 & 27.2 & 32.6 & up & up \\
\hline Urban & 37.8 & 33.5 & 41.0 & up & up \\
\hline Adequate medical care now ${ }^{d}$ & 95.9 & 88.0 & 91.6 & down & up \\
\hline Tap water now & 53.4 & 56.2 & 59.3 & up & up \\
\hline Smoke now & 20.4 & 17.2 & 17.3 & down & - \\
\hline Smoke ever & 35.4 & 32.9 & 33.4 & down & - \\
\hline Body weight $<40 \mathrm{~kg}^{\mathrm{e}}$ & 16.7 & 14.1 & 10.2 & down & down \\
\hline Body weight 40-54 kge & 54.7 & 60.9 & 55.9 & - & down \\
\hline Body weight 55-64 kge & 17.1 & 18.1 & 22.6 & up & up \\
\hline Body weight $>65 \mathrm{~kg}^{\mathrm{e}}$ & 8.2 & 7.0 & 10.7 & up & up \\
\hline
\end{tabular}

na $=$ not applicable

${ }^{\text {aW }}$ Weighted prevalences for 2000 and 2005 available from authors.

${ }^{\mathrm{b}}$ Significance of trends based on a p-value of $<0.05$ for the coefficient on a trend variable $(0=1998,2=2000$, $4=2002,7=2005,10=2008$ ) in a logit or linear regression model (as appropriate) with controls for trend, age group, sex, and institutional residence (unless the variable is the outcome variable). Sample sizes including missing are 52,789 for 1998-2008 and 33,012 for 2002-2008.

"For 1998-2005, "never sick" was a response category, in addition to "yes" and "no." These responses have been categorized as "yes."

dThe question wording for all years except 1998 is: "If you are seriously ill, can you get medical services in hospital in a timely manner?" For 1998, the wording is: "When you get sick, can you get medical care in a timely manner?" For 1998-2000, "never sick" was a response category, in addition to "yes" and "no." These responses have been categorized as "yes."

${ }^{\mathrm{e}}$ For models of trends in functional and activity limitations, a cubic specification of body weight is used, since it has a stronger association with those trends. SOURCE: CLHLS.

Limitations in IADLs (such as shopping) and ADLs (such as bathing) are a function of both underlying capacity and the demands of the specific activity in the environment in which it is carried out. Thus, IADL and ADL limitation represent more than health and may be influenced by how an activity is done (such as taking a bath in a tub or taking a shower), home modification (such as installing a shower with grab bars), or use of assistive technology (such as using a shower seat). Typically, ADL disability reflects more severe limitation than IADL disability and is experienced by a smaller proportion of the population.

For the three waves from 2002 to 2008, respondents were asked about their ability to carry out three physical functions independently: walking one 
kilometer, carrying 5 kilograms, and continuously crouching and standing three times. We constructed a summary indicator of functional limitation that was coded as one if the respondent reported inability to do any of these three functions independently, and zero otherwise. The top panel of Table 2 presents by year and sex the weighted proportions reporting limitations for the summary indicator and the annual percent change from 2002 to 2008, unadjusted for age, sex, institutional residence, or proxy reports. (The weighted prevalence for each of the individual functions and the mean number of limitations are given in Appendix Table A.1.) About 60 percent of both sexes combined reported inability with at least one of the three functions, the most difficult of which was continuously crouching and standing three times. Females were more likely to report inability than males, but the unadjusted change from 2002 to 2008 for females was -0.72 percent versus 0.02 percent for males. The mean number of functional limitations also declined for females at an unadjusted rate of almost one percent per year.

For the same three waves, respondents were asked about their ability to independently perform five IADLs: visit neighbors, cook a meal, shop, do laundry, and take public transport. Our summary indicator of IADL limitation was coded as one if the respondent reported inability to carry out at least one of these five activities independently and zero otherwise. As shown in the middle panel of Table 2, over half of the age 80-105 weighted sample reported such inability. Appendix Table A.1 indicates that the inability related to specific activities in 2008 ranged from 14 percent unable to visit neighbors to over half unable to take public transport by themselves. Again, the proportions with limitations are higher for females than for males, except for cooking and doing laundry. But for the summary outcome, the unadjusted annual rate of change was greater for males than females: -2.62 percent versus -1.39 percent. Males especially made progress in being able to do laundry and cook meals. For both sexes together, the unadjusted average annual rate of change for the mean number of IADL limitations was -2.44 percent, even greater than the change of -1.93 percent for being unable to independently do any of the five.

For all five waves from 1998 to 2008, respondents were asked about their ability to perform five ADLs without assistance: feed oneself, transfer to and from bed and chair, dress, go to the toilet, and bathe. Our summary indicator of need for assistance with ADLs was coded as one if the respondent reported need for help with one or more of these five activities, and zero otherwise. As shown in Appendix Table A.1, the most challenging activity was bathing. The unadjusted percent decline in the summary measure of ADL inability was almost twice as large for females as for males $(-3.85$ versus -1.97 percent). The unadjusted mean number of ADL limitations also declined substantially for both groups, but not at as great a rate as needing help with any of five ADLs. ${ }^{1}$ 


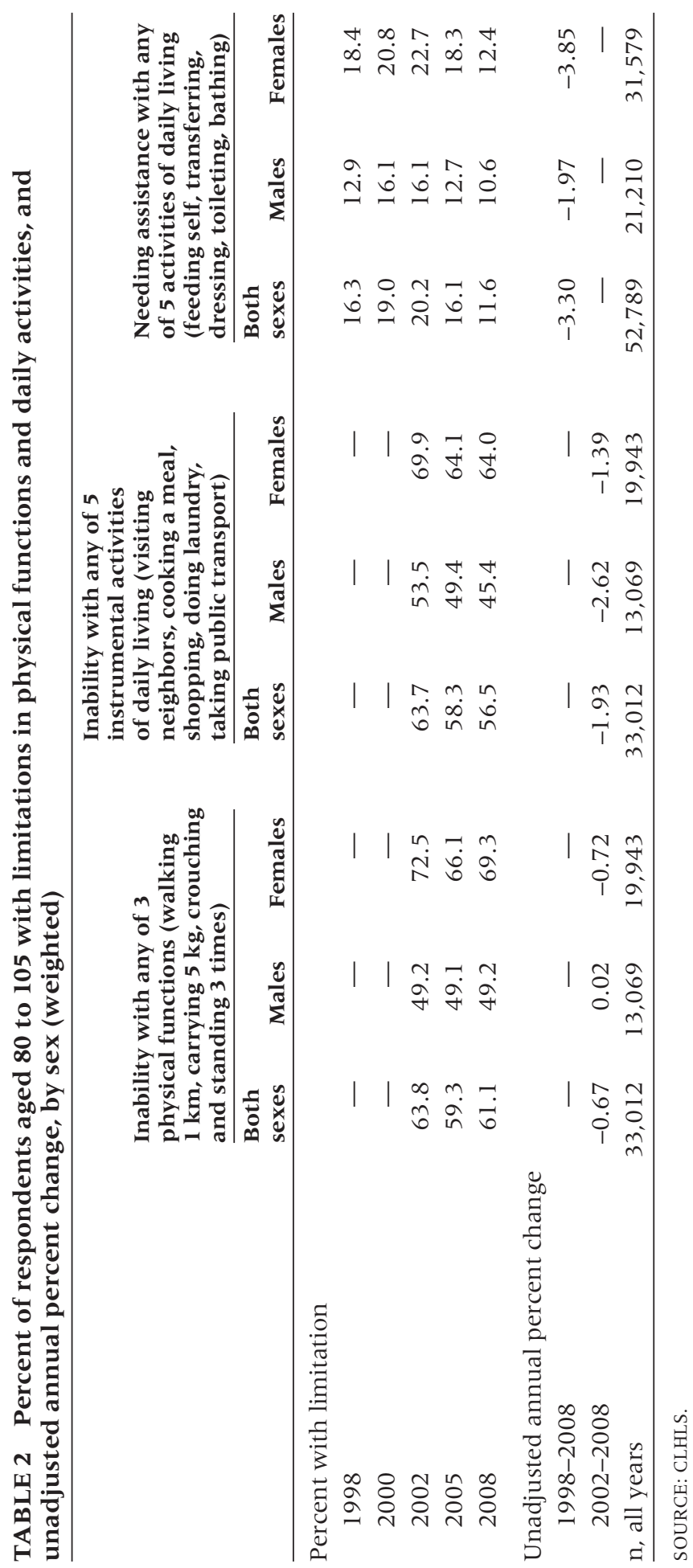




\section{Possible explanatory variables}

The CLHLS inquired about a wide range of socio-demographic characteristics and health behaviors. In identifying variables that might be associated with trends in limitations, we focused on those that have been found to have a cross-sectional relationship with our outcomes of interest. We also examined trends in the variables themselves, since, assuming no change in cross-sectional relationships over time, a variable whose distribution does not change over time is unlikely to be associated with trends in limitations. Given the many significant societal changes in China during the lifetimes of the survey respondents, we were particularly interested in how trends in early- and midlife experiences might account for trends in late-life limitations.

Table 1 presents the variables that we considered, organized by those we include in our basic control models, those whose influence begins in early life, those from the middle of life, and those from late life. For each variable, we show the unadjusted weighted prevalence for 1998, 2002, and 2008 , although in our analysis we use data for all five waves, including the two intervening years of 2000 and 2005. The table also indicates whether the prevalence of the variable changed significantly from 1998 to 2008 and from 2002 to 2008, with significance assessed as indicated in note b to Table 1. Below we comment on those trends, as well as possible relations with late-life functioning.

Among early-life variables, there was an increase over at least one of the time periods for Han ethnicity (the majority group and thus expected to be advantageous), being a male first-born (likely beneficial), having a father whose main occupation was agriculture (possibly protective in periods of famines), being right-handed (preferred culturally), and frequently going to bed hungry as a child (likely to be detrimental). Variables whose prevalence declined were urban birth (possibly advantageous) and receipt of adequate medical care as a child (advantageous). There also was a downward shift in the educational distribution of the 80-105 population from 1998 to 2008, but no change from 2002 to 2008 . The changes in father's occupation in agriculture, childhood hunger, and adequacy of medical care as a child are especially large for the ten-year period. The first two increased by more than 15 percentage points, and the last declined by 50 percentage points.

Among mid-life variables, there were increases in children ever born (could reflect robustness of mother, but also could indicate maternal depletion), main occupation before age 60 in agriculture and related fields (possibly protective during famines), doing physical labor regularly (could be beneficial, but may also represent an increased risk of injury), and using tap water for drinking at age 60 (a marker of relatively greater resources); and there was a decline in receipt of adequate medical care at age 60. Again, the changes regarding agricultural occupation and medical care are large. The increase in 
the former is driven primarily by change for females, for whom the prevalence increased from 53 percent to 74 percent over ten years.

Among late-life variables, there were increases in being married (thought to be protective), urban residence (advantageous compared to rural residence), currently drinking tap water, and the highest two categories of self-reported body weight, and decreases in smoking now or ever and the lowest two categories of body weight. Notably, adequacy of current medical care decreased from 1998 to 2008, but increased from 2002 to 2008. ${ }^{2}$

Trends in explanatory variables were generally similar for males and females, but we mention here a few instances of variables for which the trends for males and females differed. For 1998 to 2008, the trend for the second weight category (40-54 kg.) was down for males and up for females. For 2002 to 2008, for males, main occupation in agriculture was flat. For females, there was no decline in the second weight category and no increase in the top weight category for the later period.

Most of the variables have well under one percent missing values. A few-those having to do with adequacy of medical care in childhood and at age 60 , childhood hunger, and body weight—are missing one to two percent. ${ }^{3}$

\section{Statistical approach}

We fit logit models for trends in limitations for each of our three summary measures of limitations, for both sexes combined and for males and females separately. Each model includes dummy variables for survey wave. For models of limitations in physical functions and IADLs, there are dummy variables for 2005 and 2008, with 2002 the omitted category. For ADL models, 1998 is the omitted category, and there are dummy variable for each of the other four survey waves. In our basic models, we include controls for age group (as listed in Table 1), institutional residence, and female (for models including both sexes). We also include the relevant proxy response indicator for each outcome.

We use the estimated coefficients to calculate the predicted values of the outcome for each year for each observation. The weighted means of these predicted values for each year are then used to calculate the average annual percent change in the outcome, controlling for the variables in our basic model and using the average survey intervals of 10.27 years from 1998 to 2008 and 6.28 years from 2002 to 2008 .

After fitting the basic model for each outcome, we add possible explanatory variables individually to the basic model to see whether the estimated average annual percent change is substantially different. In the following, we report results for which the difference is more than 10 percent. So, for example, if the basic model yields a rate of change of -1.00 percent, we highlight variables whose addition to the basic model results in an estimated rate 
of change that is in absolute value smaller than -0.90 percent or greater than -1.10 percent. Our focus is not on testing for the statistical significance of change in the estimated rate of change, but rather in assessing the confounding influence of the additional variable. ${ }^{4}$

\section{Results}

\section{Trends in physical functional limitations}

Table 3 presents the results for physical functions. In the basic model for both sexes, the coefficient for year 2005 indicates a statistically significant decline in prevalence of limitations from 2002, but the coefficient for year 2008 indicates no difference from 2002. The resulting estimated average annual change in inability to independently carry out at least one of the three physi-

TABLE 3 Estimates from logit models of trends in inability in any of three physical functions, respondents aged 80-105, both sexes, males, and females, 2002-2008

\begin{tabular}{|c|c|c|c|}
\hline & $\begin{array}{l}\text { Both } \\
\text { sexes }\end{array}$ & Males & Females \\
\hline \multicolumn{4}{|l|}{ Coefficient $(p)$ from basic model ${ }^{a}$} \\
\hline Year 2005 & $\begin{array}{r}-0.129 \\
(.028)\end{array}$ & $\begin{array}{l}0.049 \\
(.531)\end{array}$ & $\begin{array}{r}-0.264 \\
(.002)\end{array}$ \\
\hline Year 2008 & $\begin{array}{r}-0.087 \\
(.113)\end{array}$ & $\begin{array}{l}0.027 \\
(.713)\end{array}$ & $\begin{array}{r}-0.175 \\
(.028)\end{array}$ \\
\hline $\begin{array}{l}\text { Estimated average annual } \\
\text { change (percent) }\end{array}$ & -0.48 & 0.21 & -0.78 \\
\hline \multicolumn{4}{|l|}{$\begin{array}{l}\text { Significant decline for inability } \\
\text { with individual functions }\end{array}$} \\
\hline 2005 vs. 2002 & - & - & $\begin{array}{l}\text { walk } 1 \mathrm{~km} \text {, } \\
\text { carry } 5 \mathrm{~kg}\end{array}$ \\
\hline 2008 vs. 2002 & $\begin{array}{l}\text { carry } \\
5 \mathrm{~kg}\end{array}$ & - & $\begin{array}{l}\text { walk } 1 \mathrm{~km}, \\
\text { carry } 5 \mathrm{~kg}\end{array}$ \\
\hline \multicolumn{4}{|l|}{$\begin{array}{l}\text { Estimated average annual change for } \\
\text { basic models with specific variable } \\
\text { added that results in a change in the } \\
\text { estimated average annual change of } \\
10 \% \text { or more } \text { (percent) }^{\mathrm{b}}\end{array}$} \\
\hline Adequate medical care as child & -0.59 & & -0.89 \\
\hline Childhood hunger & -0.59 & & -0.87 \\
\hline Main occupation agriculture before 60 & -0.41 & & -0.68 \\
\hline Adequate medical care now & -0.38 & & -0.69 \\
\hline Body weight $^{c}$ & -0.39 & & -0.68 \\
\hline
\end{tabular}

NOTE: P-values in parentheses.

${ }^{a}$ Basic model includes year dummy variables, age group, sex (omitted for sex-specific models), institutional residence, and proxy for responses to any of the physical function questions.

${ }^{b}$ For males, the coefficients on the year dummy variables were not significantly different from zero in any of the models, so we do not report change results here.

${ }^{c}$ Body weight is specified in the models as weight, weight squared, and weight cubed. 
cal functions is small, -0.48 percent. Among individual physical functions, only for carrying 5 kilograms is there a significant change from 2002 to 2008.

Five different variables when added to the basic model alter the estimated average annual change by 10 percent or more. Increasing the size of the change are adequate medical care as a child (whose trend is down and whose main effect on inability is borderline negative with $\mathrm{p}=.054$ (not shown)) and childhood hunger (whose trend is up and whose main effect on inability is positive). Controlling for these variables results in larger estimated declines in functional inability than in the basic model, so had these variables not changed in a detrimental fashion there would have been greater improvement in physical functioning.

Reducing the size of the estimated average annual change in physical function inability are main occupation agriculture before age 60 (whose trend is up and whose main effect on inability is negative), adequate medical care now (whose trend is up and whose main effect on inability is negative), and body weight (whose trend is up and for which the main effects of weight and weight cubed on inability are negative and the main effect of weight squared is positive). So had there not been beneficial changes in these three variables, the improvement in functioning would have been smaller.

For males, neither of the coefficients on the year dummy variables is statistically different from zero, and the estimated average annual change in physical functional difficulty is only 0.21 percent. When variables were added to the basic model, both year dummy variables remained insignificant in all cases, so we do not report results from those models.

For females, the coefficients on both year dummy variables in the model for inability related to any of three physical functions are significantly negative, indicating improved functioning from 2002 to 2008. There are also significant declines in inability for two of the individual measures, walking one kilometer and carrying 5 kilograms. The estimated average annual change in the summary indicator is -0.78 percent. As in the case of both sexes combined, two variables increase the size of the estimated rate of decline by more than 10 percent, and three reduce it similarly.

\section{Trends in IADL limitations}

Table 4 provides the results for trends in IADL inability. The coefficients on the two year dummy variables for the summary indicator for both sexes together are negative, large, and significant. The resulting estimated average annual change from 2002 to 2008 is -1.77 percent. The estimated changes for each sex are also substantial: -2.45 percent for males (although the dummy variable for 2005 is not significantly different from zero) and -1.45 percent for females. For both sexes together and for females, there are declines in inability for all five individual activities from 2002 to 2008; for males, there are declines for only three activities: shopping, cooking, and doing laundry. 
TABLE 4 Estimates from logit models of trends in inability in any of five IADLs, respondents aged 80-105, both sexes, males, and females, 2002-2008

\begin{tabular}{|c|c|c|c|}
\hline & $\begin{array}{l}\text { Both } \\
\text { sexes }\end{array}$ & Males & Females \\
\hline \multicolumn{4}{|l|}{ Coefficient (p) from basic model ${ }^{a}$} \\
\hline Year 2005 & $\begin{array}{r}-0.170 \\
(.000)\end{array}$ & $\begin{array}{r}-0.124 \\
(.125)\end{array}$ & $\begin{array}{r}-0.207 \\
(.013)\end{array}$ \\
\hline Year 2008 & $\begin{array}{r}-0.305 \\
(.000)\end{array}$ & $\begin{array}{r}-0.325 \\
(.000)\end{array}$ & $\begin{array}{r}-0.294 \\
(.000)\end{array}$ \\
\hline Estimated average annual change (percent) & -1.77 & -2.45 & -1.45 \\
\hline \multicolumn{4}{|l|}{$\begin{array}{l}\text { Significant decline (unless noted } \\
\text { otherwise) in ability for individual } \\
\text { functions }\end{array}$} \\
\hline 2005 vs. 2002 & - & visit (up) & - \\
\hline 2008 vs. 2002 & all 5 & $\begin{array}{l}\text { shop, } \\
\text { cook, } \\
\text { launder }\end{array}$ & all 5 \\
\hline \multicolumn{4}{|l|}{$\begin{array}{l}\text { Estimated average annual change for } \\
\text { basic models with specific variable } \\
\text { added that results in a change in } \\
\text { the estimated average annual } \\
\text { change of } 10 \% \text { or more (percent) }\end{array}$} \\
\hline Body weight ${ }^{b}$ & & & -1.27 \\
\hline
\end{tabular}

NOTE: P-values in parentheses.

${ }^{a}$ Basic model includes year dummy variables, age group, sex (omitted for sex-specific models), institutional residence, and proxy for responses to any of the IADL questions.

${ }^{b}$ Body weight is specified in the models as weight, weight squared, and weight cubed.

For both sexes combined and for males, none of the possible explanatory variables has a substantial effect on the estimated average annual change. For females (for whom the proportion in the under 40 kilogram weight category is down and the proportion in the 55 to 64 kilogram category is up), adding body weight (for which the main effects of weight and weight cubed on inability are negative and the main effect of weight squared is positive) results in a smaller negative trend coefficient. Thus, the change in weight distribution had a beneficial effect on the IADL trend for females.

\section{Trends in ADL limitations}

Results for trends in need for assistance with ADLs are presented in Table 5. For both sexes together, there is a significant negative coefficient on the dummy variable for 2008 and a resulting estimated average annual rate of change from 1998 to 2008 of -3.91 percent. By 2008, need for assistance with all of the individual ADLs had declined significantly. One variable increases the size of the decline: adequate medical care as a child (whose trend is down and whose main effect on need for assistance is negative). Thus, the trend in this variable was not beneficial for ADLs. Two variables reduce the size of the rate of decline by more 
TABLE 5 Estimates from logit models of trends in needing assistance with any of five ADLs, respondents aged 80-105, both sexes, males, and females, 1998-2008

\begin{tabular}{|c|c|c|c|}
\hline & $\begin{array}{l}\text { Both } \\
\text { sexes }\end{array}$ & Males & Females \\
\hline \multicolumn{4}{|l|}{ Coefficient $(p)$ from basic model ${ }^{a}$} \\
\hline Year 2000 & $\begin{array}{l}0.013 \\
(.850)\end{array}$ & $\begin{array}{l}0.031 \\
(.752)\end{array}$ & $\begin{array}{l}0.001 \\
(.989)\end{array}$ \\
\hline Year 2002 & $\begin{array}{l}0.121 \\
(.059)\end{array}$ & $\begin{array}{l}0.082 \\
(.411)\end{array}$ & $\begin{array}{l}0.139 \\
(.092)\end{array}$ \\
\hline Year 2005 & $\begin{array}{r}-0.067 \\
(.351)\end{array}$ & $\begin{array}{r}-0.159 \\
(.154)\end{array}$ & $\begin{array}{r}-0.024 \\
(.792)\end{array}$ \\
\hline Year 2008 & $\begin{array}{r}-0.521 \\
(.000)\end{array}$ & $\begin{array}{r}-0.383 \\
(.000)\end{array}$ & $\begin{array}{r}-0.600 \\
(.000)\end{array}$ \\
\hline $\begin{array}{l}\text { Estimated average annual } \\
\text { change (percent) }\end{array}$ & -3.91 & -2.98 & -4.42 \\
\hline \multicolumn{4}{|l|}{$\begin{array}{l}\text { Significant decline for inability } \\
\text { with individual functions }\end{array}$} \\
\hline 2000 vs. 1998 & $\begin{array}{l}\text { dress, } \\
\text { transfer, } \\
\text { toilet }\end{array}$ & $\begin{array}{l}\text { dress, } \\
\text { transfer }\end{array}$ & $\begin{array}{l}\text { transfer, } \\
\text { toilet }\end{array}$ \\
\hline 2002 vs. 1998 & - & - & - \\
\hline 2005 vs. 1998 & - & - & - \\
\hline 2008 vs. 1998 & all 5 & $\begin{array}{l}\text { all except } \\
\text { feed self }\end{array}$ & all 5 \\
\hline \multicolumn{4}{|l|}{$\begin{array}{l}\text { Estimated average annual change for } \\
\text { basic models with specific variable } \\
\text { added that results in a change in the } \\
\text { estimated average annual change of } \\
10 \% \text { or more (percent) }\end{array}$} \\
\hline Father's main occupation agriculture & - & -2.66 & - \\
\hline Adequate medical care as child & -4.88 & -3.94 & -5.39 \\
\hline Main occupation agriculture before 60 & -3.39 & -2.66 & -3.85 \\
\hline Body weight ${ }^{\mathrm{b}}$ & -3.47 & -2.60 & -3.96 \\
\hline
\end{tabular}

NOTE: P-values in parentheses.

${ }^{a}$ Basic model includes year dummy variables, age group, sex (omitted for sex-specific models), institutional residence, and proxy for responses to any of the ADL questions.

${ }^{b}$ Body weight is specified in the models as weight, weight squared, and weight cubed.

than 10 percent: main occupation in agriculture before age 60 (whose trend is up and whose main effect on need for assistance is negative) and body weight (whose trend is up and for which the main effects of weight and weight cubed on inability are negative and the main effect of weight squared is positive).

The estimated average annual rate of decline in the basic model is almost 50 percent larger for females than males. When specific variables are added to the basic model, the results for males and females generally follow a pattern similar to that for both sexes. The exception is that, for males, the addition to the basic model of father's main occupation in agriculture (whose trend is up and whose main effect is negative) lowers the estimated rate of 
change by more than 10 percent, indicating that the trend in the variable was advantageous.

\section{Summary and discussion}

The self-reported ability of the Chinese population at ages 80 to 105 to function and to independently carry out daily activities increased substantially over the study period. Both sexes combined and females experienced significant improvements in abilities to perform physical functions, IADLs, and ADLs, while males showed improvement in the last two. The estimated average annual rates of change (adjusted for age, sex, institutional residence, and proxy) for both sexes ranged from -0.48 percent for physical functional inability to -1.77 percent for IADL for inability and -3.91 percent for needing assistance with ADLs.

It is difficult to make comparisons internationally because of differences in survey design (e.g., inclusion or exclusion of institutionalized population), question wording (e.g., difficulty, need for help, inability), age group (e.g., $65+$ or $80+)$, time period, and other factors. Nevertheless, the estimated rates of change reported here appear to fall generally within the bounds of findings from other settings. For example, in a systematic review of studies of US trends in the 1980s and 1990s that primarily focused on people 65 and over, Freedman and colleagues (2002) documented annual changes ranging from -0.40 to -2.74 percent for IADL disability and from -1.38 to 1.53 percent for ADL disability. A more recent US analysis of 1997-2008 trends for the 65-and-over non-institutionalized population found that need for help with IADLs and ADLs changed -1.8 and -1.3 percent per year, respectively (Martin, Schoeni, and Andreski 2010). An analysis of trends in Taiwan of those 65 and over (Martin, Zimmer, and Hurng 2011) estimated annual changes of -0.73 percent for physical functional difficulty, -1.48 percent for IADL difficulty, and no significant change for ADL difficulty.

Again, such comparisons across studies should be made with caution, but it does seem that the estimated reduction in need for help with ADLs among the 80-105 Chinese population of -3.91 percent per year from 1998 to 2008 is relatively large. The change is even greater for females $(-4.42 \%)$ than for males $(-2.98 \%)$, and, as indicated by the reported coefficients for survey year, the change occurred in the second half of the period studied. Such change is consistent with the 2003-2008 increase in insurance coverage and use of hospital services for Chinese with chronic diseases (Jian et al. 2010) and the more general 2003-2011 increase in use and coverage of health care (Meng et al. 2012). However, change in self-reported adequacy of medical care was not a major factor associated with ADL trends. Moreover, one should remember that ability to carry out ADLs independently is not simply an indicator of the health of the individual: ADL limitation represents a gap between the capacity of the individual and the demands of the task as 
carried out in the particular social and physical environment (Verbrugge and Jette 1994; WHO 2002). Thus, recent changes may have occurred in how and where activities are carried out (e.g., type of toilet or bathing facilities) and in use of assistive technology (e.g., canes, walkers). Indeed, Zimmer and colleagues (2014) have speculated that the large decline from 1992 to 2007 in needing help with bathing that they found for the 70-and-over population in Beijing may be related to increased availability of private (as opposed to public) bathing facilities. In our study, we were unable to track such adjustments, which may have been made possible by increased economic resources.

More important, our analysis indicated that it is not just late-life factors that are associated with late-life trends in limitation. We found that early-, mid-, and late-life factors were all associated with trends in physical functions and ADLs. Temporal decline in reported adequacy of medical care in childhood and increase in reported childhood hunger were associated with disadvantageous trends in late-life outcomes. Had these changes not occurred, the decline in limitations would have been greater. The trend in childhood hunger was similar for all age groups, but adequacy of medical care in childhood especially deteriorated over time for age groups 80-84 and 100-105 (not shown). The younger of these two groups might have been affected by the war against the Japanese invasion of 1937-45. Those aged 80-84 in 1998 were born roughly in 1914-18, whereas those 80-84 in 2008 were born in 1924-28, so would have still been children (ages 9 to 13) at the start of the war. The trend in adequacy of medical care in childhood for the 100-105 group may have been affected by the 1911 uprising against the Qing Dynasty. Those ages 100-105 in 1998 were born around 1893-98 and would have been ages 13 to 18 at the time of the uprising, but those 100-105 in 2008 would have been ten years younger. Other researchers using the same dataset have found significant early-life effects on late-life health and mortality (Huang and Ilo 2009; Wen and Gu 2011).

Greater father's employment in agriculture and greater own employment in agriculture before age 60 were beneficial and may be related to greater physical activity or access to food. The trends in body weight are also beneficial and reflect the changing nutritional patterns of recent decades in China (Zhai et al. 2009). Self-reported adequacy of current medical care increased from 2002 to 2008 and had advantageous effects on the trend in physical functioning, especially for females. The fact that in our analysis adequacy of care is most important for physical functions (as opposed to IADLs or ADLs) has validity given that this indicator comes closest of the three outcomes to measuring underlying physical capacity. The self-reported improvement in medical care is consistent with recent national studies (Jian et al. 2010; Meng et al. 2012) that document improved insurance coverage and increased use of hospital services.

That education has no effect on the trends in functioning and daily activities is surprising in view of the important role that it has played in other populations (e.g., Martin et al. 2012; Martin, Zimmer, and Hurng 2011; 
Schoeni, Freedman, and Martin 2008). The nature of Chinese education in the early twentieth century and subsequent historic events may have resulted in the inoperability of the usual mechanisms by which education is associated with better late-life outcomes. Moreover, in this cohort of older Chinese, there was a decline in educational attainment over the study period, in contrast to the dramatic increase experienced elsewhere. This decline in education appears to be most substantial among males ages 100-105 (not shown). As in the case of adequacy of medical care in childhood, education trends for this group may have been affected by conditions surrounding the 1911 uprising. For more recently born cohorts of older people than our 80-and-over group, the role of education in disability trends may well be different. In their analysis of trends for the 70-and-over population in Beijing, Zimmer and colleagues (2014) found that having at least some education increased from 1992 to 2007 for this somewhat younger population. However, education trends were associated with ADL trends only for females.

That only the trend in one variable in our models was substantially associated with the trend in IADLs was disappointing, but the finding is similar to that of an analysis of IADLs from 1998 to 2008 among the 65-and-over population in Shanghai, China's largest city (Feng et al. 2013). We have not been able to control for changes in technology that might influence cooking and laundering or changes in environment and infrastructure that might be associated with shopping and using public transport. A recent study of latelife function in Taiwan (Martin, Zimmer, and Hurng 2011) found that such factors likely played significant roles in the decline in difficulty with IADLs.

One of the other limitations of this study is the focus on summary measures of limitation. We have not examined in depth trends in individual functions or activities. Nor have we taken into account trends in severity of limitation or number of limitations within each overarching type-physical functions, IADLs, and ADLs. The unadjusted downward trends in the summary measures of limitation parallel unadjusted downward trends in counts of limitations, but, in the case of ADLs, the decline in the mean numbers is not as great as the decline in proportions needing help with any of the five ADLs. Future analysis might benefit from greater attention to such detail and to examination of measures of physical performance.

Another study limitation is that we have had to rely on respondents' own characterizations of their earlier lives. In light of recent rapid economic growth, early-life experiences might have been viewed more critically over time, as expectations have risen. Such may especially be the case for childhood hunger and past adequacy of medical care. Nevertheless, at least for the latter, we have noted some plausible links between the trends in these variables and historical events in China.

The major strength of this study is the documentation of trends in latelife function and activity limitations for the world's largest oldest-old popu- 
lation. There is little doubt that members of this cohort have lived through and survived many challenging periods in their lifetimes. Nevertheless, we have demonstrated that the extent of late-life limitation has declined, even as people are living longer.

Our analysis indicates that were it not for the detrimental trends in such early-life factors as hunger and inadequate medical care, the declines in limitation might have been even greater. We have also shown that late-life factors such as current body weight and adequacy of medical care are positively associated with the trends in limitation. These findings provide some indication that even at very advanced ages, interventions may reduce functional and activity limitations and promote independence. Our analysis does not allow us to make policy recommendations, but the results suggest that continued improvements in nutrition and health care might be beneficial. Because information on height was not available in the CLHLS before the 2008 wave, we were unable to use body mass index in our trend analysis, but the reduction in the proportion of the oldest-old in the lowest weight category likely reflects a decline in undernutrition. On the other hand, the increase in the proportion in the highest weight category may be a worrisome sign. China is beginning to face an obesity problem (Wang et al. 2007; Wu 2006), as intake of animal food and fat increases (Zhai et al. 2009). Recent increased access to health care (Jian et al. 2010; Meng et al. 2012) augurs well for continued decline in late-life limitations, but much remains to be done to achieve the stated goal of universal access. For example, as recently as 2011 , insurance reimbursement rates for in-patient care remained below 50 percent, and over 25 percent of in-patients self-discharged for financial reasons (Meng et al. 2012).

Given the nature of IADLs and ADLs, it also seems reasonable that provision of assistive technology and modification of home environments would be helpful. Such accommodation is important in view of uncertainty about the extent to which China's future oldest-old will be able to rely on their families for personal assistance with daily activities, if needed. Some analysts have suggested that family support in rural areas especially has been jeopardized by declining economic power of the older population, rural-to-urban migration of the young, and erosion of filial piety (Chen and Liu 2009). Market or government services will face a major challenge to fill the void resulting from the decline in availability of family members, particularly as the consequences of the one-child-family policy continue to ripple up the age distribution. The financial means to purchase such services may also remain limited for some time. The ongoing pension reform in China is ambitious, but universal coverage is a distant goal (Chen and Liu 2009), especially for the oldest-old. Consequently, it is in China's interest to seek to delay or even prevent the onset of late-life limitations and to enhance the ability of its oldest citizens to live independently, rather than solely attempt to provide supportive services after the need has arisen. 


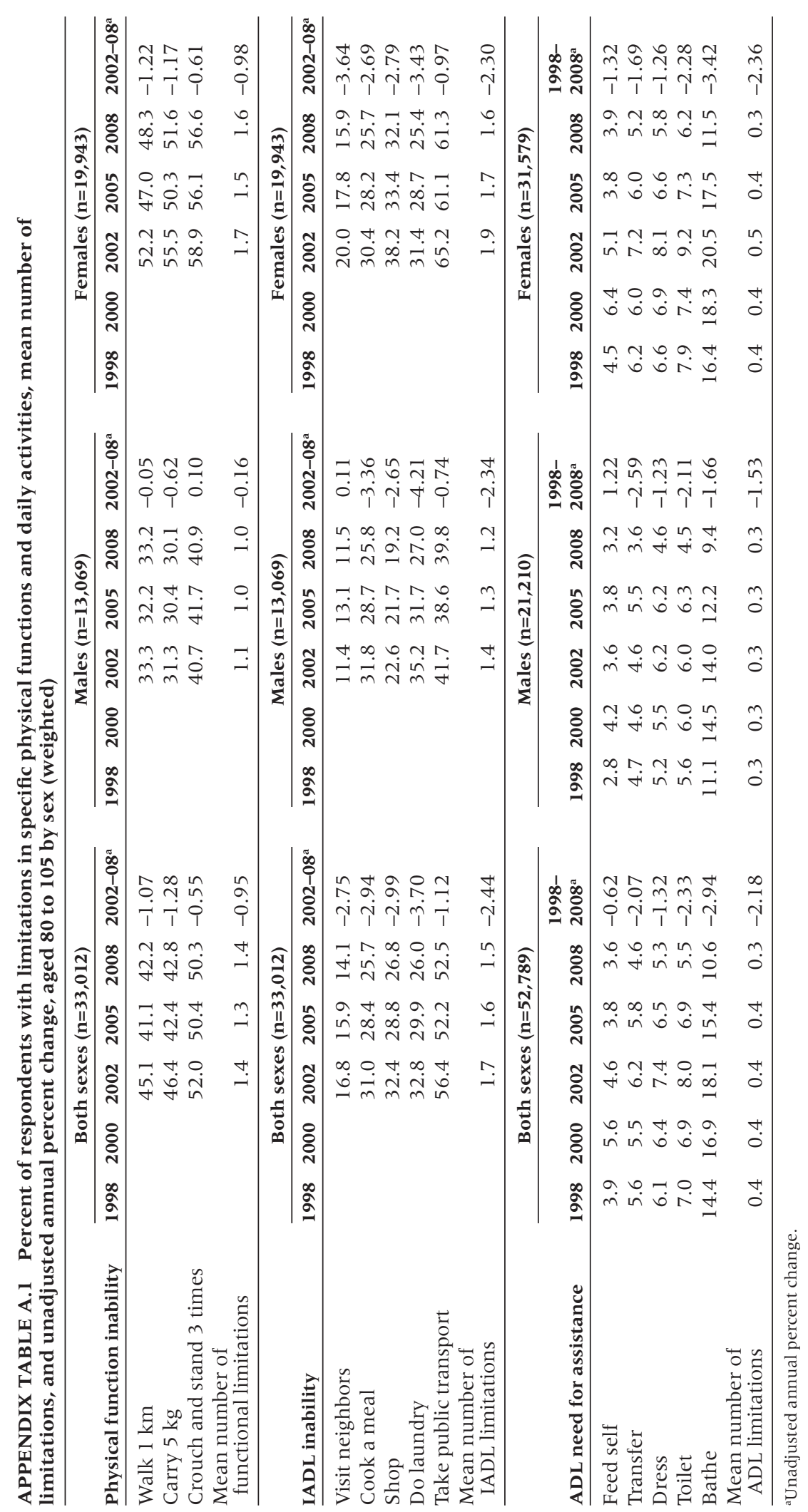




\section{Notes}

1 For all three outcome measures, less than 0.5 percent of responses were missing, and we omitted these cases from our analyses.

2 As indicated in note d to Table 1, there was a slight change in question wording for this variable between 1998 and 2000, which does not affect our models of physical function and IADLs, since they are based on data for 2002-2008. The ADL models use data for 1998-2008, but we assessed the sensitivity of our ADL results regarding this variable by restricting the relevant analysis to 2000-2008 and found no substantive difference from what is reported here.

3 For each explanatory variable, we included (besides the variable itself) a related dummy variable indicating missingness. Because of the very small numbers, these variables indicating missingness in some instances perfectly predicted the outcome. In such instances, the estimation software automatically dropped the variables indicating missingness, which resulted in the exclusion of a handful of cases for which values of the related variables were missing.

4 Care must be taken in comparing coefficients across logistic models, because the variance of the outcome (a component of the coefficient estimation) changes as variables are added to models (Winship and Mare 1984). Accordingly, we also fit the models using linear regression (in which there is no change in the variance of the outcome from model to model). This sensitivity analysis indicated no difference from the substantive results reported here. For ADL limitations for which we have data from 1998 to 2008, we also checked the sensitivity of our basic model results to excluding the first year and starting the analysis in 2000 , but found no substantial differences. For all models, standard errors are adjusted to account for multiple observations of some individual respondents across survey waves.

\section{References}

Banister, Judith and Kenneth Hill. 2004. “Mortality in China 1964-2000," Population Studies 58(1): 55-75.

Cai, Yong and Wang Feng. 2005. "Famine, social disruption, and involuntary fetal loss: Evidence from Chinese survey data," Demography 42(2): 301-322.

Chen, Feinian and Guangya Liu. 2009. "Population aging in China," in Peter Uhlenberg (ed.), International Handbook of Population Aging. Dordrecht, The Netherlands: Springer, pp. 157-172.

CLHLS Research Group. 2012. Chinese Longitudinal Healthy Longevity Survey (CLHLS). http: // centerforaging.duke.edu/chinese-longitudinal-healthy-longevity-survey. Accessed 24 April 2014.

Dong, Zhe and Michael R. Phillips. 2008. "Evolution of China's health care system," Lancet 372: 1715-1716.

Du, Juan. 2009. "Economic reforms and health insurance in China," Social Science $\theta$ Medicine 69: 387-395.

Feng, Qiushi, Zhihong Zhen, Danan Gu, Bei Wu, Pamela Duncan, and Jama L. Purser. 2013. "Trends of ADL and IADL disabilities in community-dwelling Shanghai older adults, 1998 to 2008," Journal of Gerontology 68(3): 476-485.

Freedman, Vicki A. et al. 2004. "Resolving inconsistencies in old-age disability trends: Report from a technical working group," Demography 41(3): 417-441.

Freedman, Vicki A. et al. 2013. "Trends in late-life activity limitations: An update from five national surveys," Demography 50(2): 661-671.

Freedman, Vicki A., Linda G. Martin, and Robert F. Schoeni. 2002. "Recent trends in disability and functioning among older U.S. adults," Journal of the American Medical Association 288(24): 3137-3146. 
Freedman, Vicki A., Linda G. Martin, Robert F. Schoeni, and Jennifer Cornman. 2008. “Declines in late-life disability: the role of early- and mid-life factors," Social Science and Medicine 66(7): 1588-1602.

Fries, James F. 1980. "Aging, natural death and the compression of morbidity," New England Journal of Medicine 303: 130-35.

Gruenberg, Ernest M. 1977. "The failures of success," Milbank Memorial Fund Quarterly 55: 3-24.

Hesketh, Therese, and Wei Xing Zhu. 1997. "Health in China: From Mao to market reform," British Medical Journal 314: 1543-1545.

Huang, Cheng, and Irma T. Elo. 2009. "Mortality of the oldest old Chinese: the role of early-life nutritional status, socio-economic conditions, and sibling sex-composition." Population Studies 63(1): 7-20.

Jian, Weiyan, Kit Yee Chan, Daniel D. Reidpath, and Ling Xu. 2010. “China's rural-urban care gap shrank for chronic disease patients, but inequities persist," Health Affairs 29(12): 2189-2196.

Manton, Kenneth G. 1982. "Changing concepts of morbidity and mortality in the elderly population." Milbank Memorial Fund Quarterly 60: 183-244.

Manton, Kenneth G., and Xiliang Gu. 2001. "Changes in the prevalence of chronic disability in the United States black and nonblack population above age 65 from 1982 to 1999," Proceedings of the National Academy of Sciences USA 98(11): 6354-6359.

Martin, Linda G., Robert F. Schoeni, and Patricia M. Andreski. 2010. “Trends in health of older adults in the United States: past, present, future," Demography 47(Supp): S17-S40.

Martin, Linda G., Robert F. Schoeni, Patricia M. Andreski, and Carol Jagger. 2012. “Trends and inequalities in late-life health and functioning in England," Journal of Epidemiology and Community Health 66: 874-880.

Martin, Linda G., Zachary Zimmer, and Baai-Shyun Hurng. 201 1. "Trends in late-life disability in Taiwan, 1989-2007: The roles of education, environment, and technology," Population Studies 65(3): 289-304.

Meng, Qun, Ling Xu, Yaoguang Zhang, Juncheng Qian, Min Cai, Ying Xin, Jun Gao, Ke Xu, J. Ties Boerma, and Sarah L. Barber. 2012. "Trends in access to health services and financial protection in China between 2003 and 2011 : A cross-sectional study," The Lancet 379(9818): 805-814.

Moise, Edwin E. 1977. "Downward social mobility in pre-revolutionary China," Modern China 3(1):3-31.

Parker, Marti G., Pär Schön, Mårtin Lagergren, and Mats Thorslund. 2008. "Functional ability in the elderly Swedish population from 1980 to 2005," European Journal of Ageing 5(4): 299-309.

Peng, Xizhe. 1987. “Demographic consequences of the Great Leap Forward in China's provinces," Population and Development Review 13(4): 639-670.

Picavet, H.S.J., and N. Hoeymans. 2002. "Physical disability in The Netherlands: Prevalence, risk groups and time trends," Public Health 116: 231-237.

Schoeni, Robert F, Vicki A. Freedman, and Linda G. Martin. 2008. "Why is late-life disability declining?" Milbank Quarterly 86(1): 47-87.

Schoeni, Robert F, Jersey Liang, Joan Bennett, Hidehiro Sugisawa, Taro Fukaya, and Erika Kobayashi. 2006. "Trends in old-age functioning and disability in Japan, 1993-2002," Population Studies 60(1): 39-54.

Sulander, Tommi, Tuija Martelin, Päivi Sainio, Ossi Rahkonen, Aulikki Nissinen, and Antti Uutela. 2006. "Trends and educational disparities in functional capacity among people aged 65-84 years," International Journal of Epidemiology 35: 1255-1261.

United Nations Department of Economics and Social Affairs. 2011. World Population Prospects: The 2010 Revision. New York: United Nations.

Verbrugge, Lois M., and Alan M. Jette. 1994. "The disablement process," Social Science and Medicine 38(1): 1-14.

Wang, Haidong, Laura Dwyer-Lindgren, Katherine T. Lofgren, Julie Knoll Rajaratnam, Jacob R. Marcus, Alison Levin-Rector, Carly E. Levitz, Alan D. Lopez, and Christopher J.L. 
Murray. 2012. “Age-specific and sex-specific mortality in 187 countries, 1970-2010: A systematic analysis for the Global Burden of Disease Study 2010," Lancet 380: 2071-2094.

Wang, Y., J. Mi, X. Shan, Q.J. Wang, and K. Ge. 2007. "Is China facing an obesity epidemic and the consequences: The trends in obesity and chronic disease in China," International Journal of Obesity 31: 177-188.

Wen, Ming, and Danan Gu. 2011. "The effect of childhood, adult, and community socioeconomic conditions on health and mortality among older adults in China," Demography 48: 153-181.

Winship, Christopher, and Robert D. Mare. 1984. "Regression models with ordinal variables," American Sociological Review 49: 512-525.

World Health Organization (WHO). 2002. "Towards a common language for functioning, disability and health: ICF 2002." http: //www.who.int/classifications/icf/training/icfbegin nersguide.pdf. Accessed 24 April 2014.

Wu, Yangfeng. 2006. "Overweight and obesity in China," British Medical Journal 333(August 19): 362-363.

Yang, Dennis T. 1999. "Urban-biased policies and rising income inequality in China," American Economic Review 89(2): 306-310.

Yang, Gonghuan, Yu Wang, Yixin Zeng, George F. Gao, Xiaofeng Liang, Maigeng Zhou, Xia Wan, Shicheng Yu, Yuhong Jiang, Mohsen Naghavi, Theo Vos, Haidong Wang, Alan D. Lopez, and Christopher J.L. Murray. 2013. “Rapid health transition in China, 1990-2010: Findings from the Global Burden of Disease Study 2010," Lancet 381: 1987-2015.

Zhai, Fengying, Huijung Wang, Shufa Du, Yuna He, Zhihong Wang, Keyou Ge, and Barry M. Popkin. 2009. "Prospective study on nutrition transition in China," Nutrition Reviews 67 (Supp. 1): 556-561.

Zhao, Zhongwei. 2006. "Income inequality, unequal health care access, and mortality in China," Population and Development Review 32(3): 461-483.

Zimmer, Zachary, Xianghua Fang, and Zhe Tang. 2014. "Fifteen-year disability trends among older persons in the Beijing Municipality of China," Journal of Aging and Health 26(2): 207-230. 